\title{
Corrosion Resistance of MB8 Magnesium Alloy after Ultrasonic Impact Treating
}

\author{
Bolin $\mathrm{He}^{1, \mathrm{a}}$, Songsong $\mathrm{XI} \mathrm{A}^{1, \mathrm{~b}}$, Yingxia $\mathrm{Yu}^{1, \mathrm{c}}$, Zhaoxia Chen ${ }^{1, \mathrm{~d}}$ \\ and Jianping $\mathrm{Shi}^{2, \mathrm{e}}$ \\ ${ }^{1}$ Key Laboratory of Ministry of Education for Conveyance and Equipment, East China Jiaotong \\ University, Nanchang 330013, China \\ ${ }^{2}$ China academy of railway sciences, Beijing 100081 China \\ ahebolin@163.com, b807564262@qq.com, ${ }^{\mathrm{c} y y x h b l @ 163 . c o m, ~}{ }^{\mathrm{d}}$ \\ czx79@126.com, eshijianping@rails.com.cn
}

Keywords: Corrosion resistance, MB8 Magnesium Alloy, Ultrasonic impact, Residual stress, Microstructure

\begin{abstract}
MB8 magnesium alloy was treated by using HJ-III type ultrasonic impact treatment machine. The effect of ultrasonic impact treatment parameters on the microstructure, residual stress in the surface and corrosion resistance was investigated. The test results indicate that the grain in the treated area was refined and residual compressive stress in the treated surface was formed. The thickness of the plastic deformation layer is about $260 \mu \mathrm{m}$. The corrosion resistance was increased to a different degree. When the ultrasonic impact treatment current was $1.2 \mathrm{~A}$, the impact time was $6 \mathrm{~min}$, comparing to the untreated specimen, the corrosion resistance of treated specimen has been increased by $51.25 \%$. The main reason for promote the corrosion resistance is grain refining and residual compressive stress which induced by ultrasonic impact treatment.
\end{abstract}

\section{Introduction}

Magnesium alloy has the advantages of light weight, high specific strength, high specific stiffness, and low price. It is the ideal material of environmental protection, which are taken as the major project of the "The 12th Five Year Plan”. It can meet the need of light weight and energy conservation in the fields of plane, automobile, motorcycle. Also it has the characteristic easy molding processing and easy recovery [1]. So it is widely used in the field of automobile, aviation, electronics, communication recently [2-5]. At present, the industrial application of magnesium alloy is cast magnesium alloy. When it was taken as structural material of vehicle, it also exits some problems. Magnesium alloy has close-packed hexagonal lattice, so deformation mechanism is complex and has poor ductility. The chemical property of magnesium is active. It is easily prone to oxidation reaction and electrochemical reaction, causing corrosion of materials. Similar to the pure magnesium, magnesium alloy corrosion potential is very low and has poor corrosion resistance. Magnesium and magnesium alloy are easy to be oxidized by oxygen in air at room temperature, producing the oxide film. Compared with the aluminum and aluminum alloy oxide film, the oxide film is loose and porous, brittleness and poor corrosion resistance. So we use surface treatment to improve its corrosion resistance ability [6]. The shortcomings of magnesium alloy limit its using [7-9]. In recent ten years, development and application of magnesium alloy materials entering the critical stage, becoming the new focus of technology and industry field. Countries have invested a lot of manpower and material resources to conduct the research to it and many research results have been applied to some fields [10-16]. Ultrasonic impact is developed to be a special surface strengthening technology in recent years. It adopts mechanical impact to make the surface of the metal material to produce large plastic deformation, thus refining surface metal tissue, improving the strength of surface [17-20]. In addition, he also can produce surface residual compressive stress [21]. Different from other nanophase materials preparation methods, surface self nanophase materials with conventional surface treatment technology of surface treatment technology improvement can be 
achieved. Surface nano-crystallization of material microstructure along the thickness direction is a gradient changes and does not occur delamination and separation in the use process. This test applies ultrasonic impact treatment to MB8 magnesium alloy, studying the microstructure, residual stress on the surface and corrosion resistance under different ultrasonic impact parameters. This test will proved some according for the using of MB8 magnesium alloy in industry.

\section{Experiments}

Experimental materials. Test material is MB8 magnesium alloy. Chemical composition and mechanical properties was shown in Table 1 and Table 2.

\begin{tabular}{ccccc}
\multicolumn{4}{c}{ Table 1 Chemical composition of MB8 (mass fraction, \%) } \\
\hline $\mathrm{Mn}$ & $\mathrm{Ce}$ & $\mathrm{Al}$ & $\mathrm{Zn}$ & $\mathrm{Mg}$ \\
\hline 1.9 & 0.22 & 0.25 & 0.30 & Balance \\
\hline
\end{tabular}

Table 2 Mechanical properties of MB8

\begin{tabular}{ccccc}
\hline $\mathrm{E} / \mathrm{MPa}$ & $\sigma \mathrm{s} / \mathrm{MPa}$ & $\sigma \mathrm{b} / \mathrm{MPa}$ & $\delta / \%$ & $v$ \\
\hline $4.5 \times 10^{4}$ & 146 & 239 & 11 & 0.33 \\
\hline
\end{tabular}

Ultrasonic impact test. Using ultrasonic impact machine, the impact of the gun in the impact process of MB8 magnesium alloy specimens alignment to be washed surface, applied with a certain pressure force, so that the impact of gun in the treatment process of the basic conditions in weight. The main process parameters of ultrasonic impact include the impact energy (current, amplitude), the punch diameter and the impact time. The impact of high energy is realized by controlling the current, mainly reflecting changes in the amplitude of the impact energy. The punch is generally divided into single and multiple punches, single punch diameter is 6-8mm, and multiple punches are constituted by a plurality of parallel diameter $2.5-4.5 \mathrm{~mm}$. Impact time reflects degree of metal deformation and strengthening. Ultrasonic impact machine adopts multiple punches in this experiment, the impact of current was 1.2A, and the impact time was 2, 4 and $6 \mathrm{~min}$, respectively. The UIT equipment is shown in Fig. 1 and the UIT tool and pins with the diameter $\varphi=3$ $\mathrm{mm}$ is shown in Fig. 2.The circular fillet of all the specimens were grinded smoothly in order to prevent the fracture in the position. The specimen is shown in Fig.1.

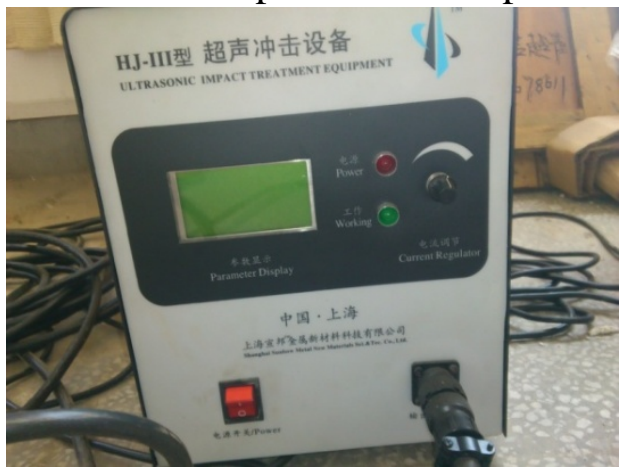

Fig.1. HJ-III type ultrasonic impact equipment

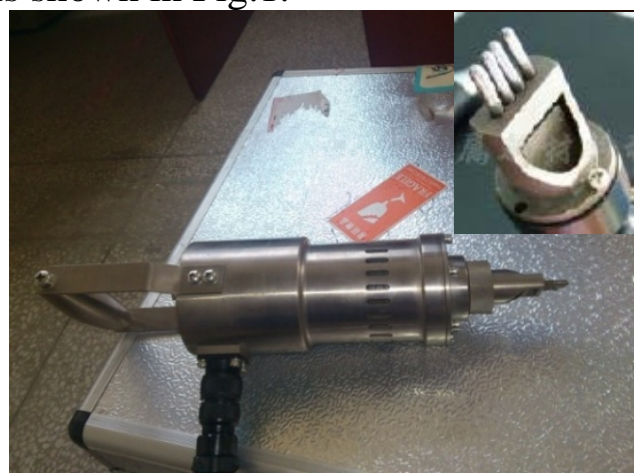

Fig.2. UIT tool and pins

Microstructure test procedures. The microstructure of cross section of base metal and treated surface of welded butt joint was observed using the optical microscope of Axio Vert.A1 type (made by Carl Zeiss, Germany).

Residual stress test procedures. The residual stress on the surface of the welded cruciform joints can be changed by ultrasonic impact treatment process. In order to understand the effect of residual stress on the fatigue properties of the welded cruciform joints, the residual stresses in the surface of the treated and un-treated specimens are measured by means of X-350 type X-Ray Stress Analyzer (made by Aisite, China). 
Corrosion test. In this experiment, the concentration of $3.5 \% \mathrm{NaCl}$ solution is used as corrosion agent. Before corrosion test, anhydrous alcohol was used to clean the specimen surface, and a sense of weight 1/10000 of ESJ205-4 type electronic balance was used to weighing out the weight of the sample (3 times for the average). Ultrasonic impact treatment and without ultrasonic impact surface of the sample immerse in corrosion solution, the remaining few surfaces are respectively coated with 502 glue to avoid corrosion. Corrosion time was 72h. After corrosion test, each specimen is weighed 3 times, and then taken the average.

\section{Test results and Analysis}

Microstructure and analysis. After impact treating on the surface of the MB8 magnesium alloy, surface microstructure was refined obviously, as shown in Fig. 3. After ultrasonic impact treatment, severe plastic deformation was produced in the surface of MB8 magnesium alloy, the depth of the plastic deformation layer is about 100,180 and $240 \mu \mathrm{m}$, respectively when the impact current is $1.2 \mathrm{~A}$, and impact time is 2, 4 and $6 \mathrm{~min}$, respectively.
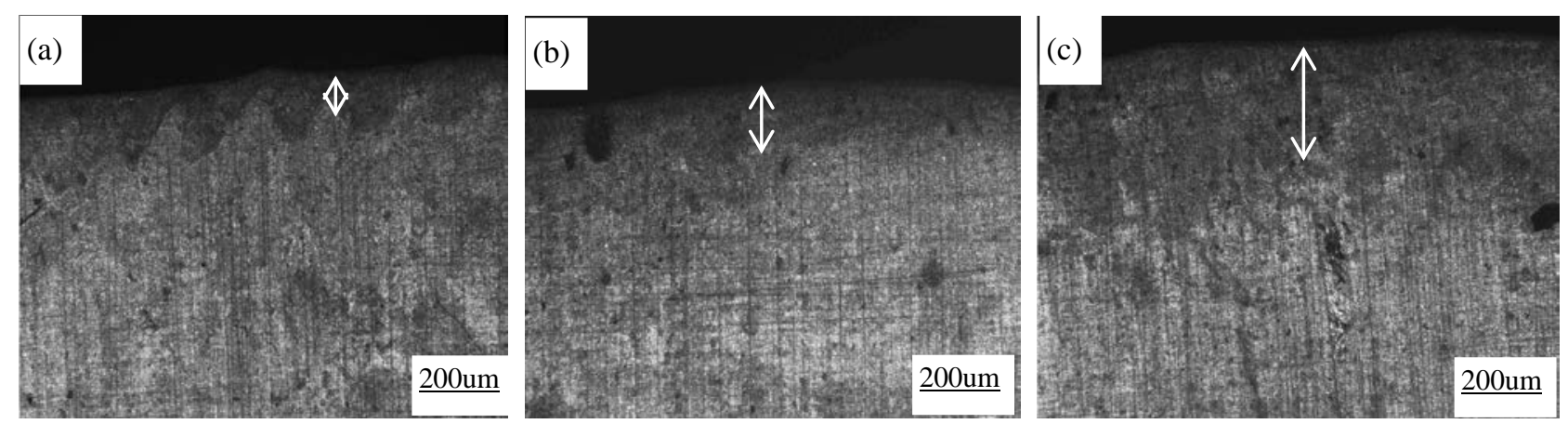

Fig.3Microstructure of treated surface (a) $1.2 \mathrm{~A} / 2 \mathrm{~min}$; (b) $1.2 \mathrm{~A} / 4 \mathrm{~min}$; (c) $1.2 \mathrm{~A} / 6 \mathrm{~min}$

Corrosion test results and analysis. In order to research the effect of ultrasonic impact treating on the corrosion resistance of MB8 magnesium alloy, corrosion tests were investigated when the when the ultrasonic impact treatment current is $1.2 \mathrm{~A}$, and impact time is $2 \mathrm{~min}$, $4 \mathrm{~min}$ and $6 \mathrm{~min}$, respectively. The corrosion test time for every specimen was 72 hours. The test results was shown in Table 3.

Table 3 The corrosion test results

\begin{tabular}{cc}
\hline Impact time/ min & Average corrosion mass/g \\
\hline 0 & 0.1122 \\
2 & 0.0847 \\
4 & 0.0682 \\
6 & 0.0547 \\
\hline
\end{tabular}

The mass of untreated specimen has changed $0.1122 \mathrm{~g}$ in corrosion solution after 72 hour. When the ultrasonic impact treatment current is $1.2 \mathrm{~A}$, and impact time is $2 \mathrm{~min}$, 4min and 6min, respectively, the mass of treated specimen decreased by $0.0847 \mathrm{~g}, 0.0682 \mathrm{~g}$ and $0.0547 \mathrm{~g}$, respectively. Compared to the untreated specimen, the mass loss for the 2, 4, and 6 min treating specimen was decresed by $24.51 \%, 39.22 \%$ and $51.25 \%$, respectively. Table 3 showns that the corrosion resistance of MB8 magnesium alloy could be improved obviously by ultrasonic impact treatment. The longer the ultrasonic impact time, the higher the corrosion resistance of the treated surface.

Residual stress test results and analysis. In order to understand the effect of ultrasonic impact treatment on the residual stress of the MB8 magnesium alloy, the ultrasonic impact treatment was carried out on the surface of MB8 magnesium alloy, and residual stress after ultrasonic impact treatment is measured by means of PSF/MSF-3M X-Ray Stress Analyzer, test results are presented in Table. 4. The residual stress on the untreated surface is positive. The results shows that the tensile residual stress on the original surface of MB8 magnesium alloy could be changed into the 
compressive stress state by ultrasonic impact treating and the values of compressive stress are bigger. When the processing time is $6 \mathrm{~min}$ and the current is $1.2 \mathrm{~A}$, the longitudinal residual stress of surface reached -31MPa. Severe plastic deformation on the treated surface is formed after ultrasonic impacting, but in the low layer of structures where occurring smaller plastic deformation or not, it would restrict the surface of plastic deformation. The constraint is attributed to the increased larger compressive stress on the surface.

Table 4 The surface residual stress of MB8 magnesium alloy after UIT

\begin{tabular}{cccc}
\hline Direction of stress & Impact 2min & Impact 4min & Impact 6min \\
\hline Transverse residual stress & $6 \mathrm{MPa}$ & $14 \mathrm{MPa}$ & $-5 \mathrm{MPa}$ \\
Longitudinal residual stress & $8 \mathrm{MPa}$ & $-14 \mathrm{MPa}$ & $-31 \mathrm{MPa}$ \\
\hline
\end{tabular}

Ultrasonic impact can not only refine the grains in the surface of MB8 magnesium alloy, but also cause larger residual compressive stress in the surface. There are two reasons lead to improve the surface corrosion resistance of MB8 magnesium alloy. Tab. 3 and Tab.4 show those significant relationships between the residual compressive stress and the corrosion resistance which is formed on the treated surface. When the ultrasonic impact treatment current is $1.2 \mathrm{~A}$, and impact time is $6 \mathrm{~min}$, the specimen surface residual compressive stress reaches the maximum absolute value.

All the analysis shows that a certain plastic deformation occurs on the treated surface of MB8 magnesium alloy, and the residual compressive stress is formed after ultrasonic impact treating. There are close relationships between the corrosion resistance increase and the residual compressive stress which is formed on the treated surface. The micro-hardness and corrosion resistance of MB8 magnesium alloy improves obviously by ultrasonic impact treatment.

\section{Conclusions}

(1)The results indicates that severe plastic deformation and residual compressive stress on the treated surface is formed after ultrasonic impacting, the depth of deformed layer was about 260um and the grain in the treated area is refined. The micro-hardness and corrosion resistance increase to different degrees.

(2)The ultrasonic impact method is very useful for improving the residual stress. Compared to the sample without treatment, the tensile residual stress can be changed to compressive residual stress when the impact time was $6 \mathrm{~min}$.

(3) When the ultrasonic impact treatment current is $1.2 \mathrm{~A}$, and impact time is $6 \mathrm{~min}$, compared with the untreated specimen, the corrosion resistance of treated specimen increase $51.25 \%$, when $3.5 \%$ $\mathrm{NaCl}$ solution is introduced. The main reason for promote the corrosion resistance is grain refining and residual compressive stress which induced by ultrasonic impact treatment. There are close relationships between the corrosion resistance increase and the residual compressive stress which is formed on the treated surface..

\section{Acknowledgements}

The research was sponsored by the National Nature Science Foundation (No.51265013), Natural Science Foundation of Jiangxi Province (No.20114BAB206020), Science Foundation of education office of Jiangxi Province (GJJ12302) and visiting scholar plan of universities in Jiangxi province.

\section{References}

[1] Libo Song: Taiyuan University of Science and Technology Master Thesis (2011), p. 4-5.

[2] Dingfei Zhang and Jian Peng: Materials Review Vol. 18 (2004), p.72-76.

[3] Bingtao Zi and Hui Wang: Rare Metals Vol. 18 (2004), p.229-232. 
[4] Mordike.B.L and Ebert.T: Materials Science and Engineering Vol. 302 (2001), p. 37-45.

[5] Agnew.S.R, Mehrotra.P, and Lillo.T.M: Acta Materialia Vol.53 (2005), p. 3135-3146.

[6] Zhenhua Chen: Wrought Magnesium Alloy (Chemical Industry Press, Beijing 2005).

[7] Lim.C.Y.H, Lim.S.C and Gupta.M: Wear Vol. 255 (2003): p. 629-637.

[8] Mondal.A.K and Kumar.S:Wear Vol. 267 (2009): p. 458-466.

[9] Chen.T.J, Ma.Y and Li. B: Materials Science and Engineering A (2007), p. 445-446.

[10] Qudong Wang, Yi Zhen and Xiaoqin Zeng: Materials Review Vol. 14 (2000), p.22-24.

[11] Xiaomin Li: Light Metals Vol. 7 (2003), p.37-38.

[12] Changrui Liu, Bojian Wang and Yubang Hu: Aluminum Magnesium Communication Vol. 2 (2001), p.53-55.

[13] Kim.D.H, Shin.K.S and Kim.N.J:Advanced Performance Materials Vol. 5 (1998), p.319-329.

[14] Zhang.P and Zeng.D.B: Special Casting \& Nonferrous Alloys, Vol. 6 (2000), p.55-57.

[15] Xiaopeng Cui: Jilin University Doctoral Dissertation (2006),p.35-36.

[16] Xitai Sun: Material surface strengthening technology (Chemical Industry Press, Beijing 2005).

[17] Lu.K and Lu.J: Materials Science and Engineering A Vol. 375-377 (2004), p. 38-45.

[18] He.B.L, Liu.J andWang B: Applied Mechanics and Materials Vol. 80-81 (2011), p.673-677.

[19] Zhanming Li, Youli Zhu and Kailiang Liu: Hot Working Technology Vol. 41 (2012), p. 151-153.

[20] Xuejian Xiang, Yuanlin Huang and Youli Zhu: Hot Working Technology Vol. 40 (2011), p. $122-124$.

[21] Peipei Wu, Aiqin Tian and Ying Wu: Hot Working Technology Vol. 43 (2014), p. 37-40. 